\title{
CONTRAdições PRESENTES NA PERCEPÇÃo DE ESTUDANTES SECUNDARISTAS DE UMA ESCOLA ESTADUAL do Município de CAMPo Verde-MT SOBRE O TEMA AGROTÓXICOS
}

\author{
CONTRADICTIONS PRESENT IN THE PERCEPTION OF SECONDARY \\ STUDENTS OF A STATE SCHOOL IN THE MUNICIPALITY OF CAMPO VERDE- \\ MT ABOUT THE PESTICIDES THEME
}

DOI: http://dx.doi.org/10.23926/RPD.2526-2149.2020.v5.n1.p391-411.id647

\section{Núbia Duarte da Cruz \\ Mestranda em Ensino de \\ Ciências Naturais \\ (PPGECN/UFMT) \\ Professora da Rede Estadual de Educação (SEDUC/MT) \\ nubiadc78@gmail.com}

\section{Glesia Gomes da \\ Costa Messias}

Mestranda em Educação

(PPGE/UFMT)

Professora da Rede Estadual de Educação (SEDUC-MT)

glesia@ hotmail.com

\section{Marcel Thiago \\ Damasceno Ribeiro}

Pós-doutorando em

Educação em Ciências e

Matemática

(PPGECM/UFG)

Doutor em Educação em

Ciências e Matemática

(REAMEC/UFMT)

Professor da Universidade

Federal de Mato Grosso

(UFMT)

marceldamascenoribeiro@g mail.com

\begin{abstract}
Resumo: Esta pesquisa tem por objetivo analisar quais são as contradições presentes nas percepções dos estudantes do terceiro ano do Ensino Médio de uma escola situada no município de Campo Verde - MT, sobre os agrotóxicos e sua relação com o meio ambiente, a saúde humana e a Química. Adotou-se uma abordagem qualitativa, cujo percurso metodológico consistiu na aplicação de um questionário e análise textual discursiva do mesmo. Os agrotóxicos fazem parte do cotidiano dos estudantes residentes no município, cuja base econômica é a agricultura. Como resultado se percebe que os estudantes apresentam um nível de conhecimento prévio satisfatório sobre os agrotóxicos, embora haja muitas contradições em suas percepções e o tema não esteja presente na maioria dos livros didáticos. Portanto, é necessário realizar processos de informação e sensibilização quanto aos aspectos atitudinais e aos conhecimentos científicos, considerando a abordagem CTSA, o contexto dos estudantes e o tema controverso que envolve os agrotóxicos.
\end{abstract}

Palavras-chave: Agrotóxicos; Contradição; CTSA; Ensino de Química.

\begin{abstract}
This research aims to analyze what are the contradictions present in the perceptions of third year high school students of a school located in the municipality of Campo Verde - MT, pesticides and their relationship with the environment, human health and Chemistry. A qualitative approach was adopted, whose methodological path consisted of the application of a questionnaire and discursive textual analysis of the same. Pesticides are part of the daily lives of students residing in the municipality, whose economic base is agriculture. As a result, it was noticed that students have a satisfactory level of prior knowledge about pesticides, although there are many contradictions in their perceptions and the theme is not present in most textbooks. Therefore, it is necessary to carry out information and awareness processes regarding attitudinal aspects and scientific knowledge, considering the CTSA approach, the students' context and the controversial topic involving pesticides.
\end{abstract}

Keywords: Pesticides; Contradiction; CTSA; Chemistry teaching. 


\section{INTRODUÇÃO}

Este artigo traz um recorte da dissertação de mestrado intitulada: Tema sociocientífico em Ciências Naturais: Proposta de um Paradidático para o Estudo dos Agrotóxicos ${ }^{1}$, que tem como objetivo principal a elaboração de uma ferramenta (livro paradidático) que auxilie os professores a trabalharem conceitos de Química e Biologia, articulando conhecimentos científicos com fenômenos presentes no cotidiano dos estudantes do Ensino Médio de uma escola estadual do município de Campo Verde - Mato Grosso (MT).

Mato Grosso (MT) é o maior produtor de soja e algodão do Brasil, segundo o último censo agropecuário realizado pelo Instituto Brasileiro de Geografia e Estatística (IBGE) em 2017. O Estado possui uma grande extensão de área cultivada e utiliza tecnologia de ponta que, associada às condições climáticas, propiciam alta produtividade. Campo Verde, município situado no Sudeste deste Estado, com uma população estimada de 42.871 habitantes no ano de 2018, segundo o último censo do IBGE, sendo o terceiro maior produtor de grãos de MT, possui na agricultura sua principal base econômica. Além da produção em grande escala, o município de Campo Verde também possui vários assentamentos, nos quais a produção de hortaliças se destaca. Com todo esse cenário agrícola, o tema agrotóxico é presente no cotidiano de todos os moradores da cidade.

Por meio de várias pesquisas realizadas por órgãos responsáveis como $\mathrm{Anvisa}^{2}, \mathrm{FAO}^{3} \mathrm{e}$ $\mathrm{OMS}^{4}$, verifica-se que a utilização dos agrotóxicos nas plantações é um problema de dimensões globais e sociais. Mesmo com reconhecida importância, esse assunto ainda é pouco discutido de maneira profunda e científica nos meios de comunicação e no meio educacional (FERNANDES; STUANI, 2015).

Diante desse cenário, o objetivo desta investigação é analisar as contradições presentes nas percepções que os estudantes do terceiro ano do Ensino Médio de uma escola estadual, situada no município de Campo Verde (MT), externam sobre os agrotóxicos, sua relação com o meio ambiente, a saúde humana e a Química. As questões a serem investigadas são os

\footnotetext{
${ }^{1}$ A pesquisa de mestrado profissional se encontra em desenvolvimento com o início em fevereiro de 2019, pelo Programa de Pós-Graduação em Ensino de Ciências Naturais (PPGECN) da Universidade Federal de Mato Grosso, campus Cuiabá.

${ }^{2}$ Agência Nacional de Vigilância Sanitária: órgão que tem por finalidade institucional promover a proteção da saúde da população, por intermédio do controle sanitário da produção e consumo de produtos e serviços submetidos à vigilância sanitária.

${ }^{3}$ Organização das Nações Unidas para a Alimentação e a Agricultura: Órgão internacional que trabalha no combate à fome e à pobreza, promovendo o desenvolvimento sustentável da agricultura de modo a preservar os recursos naturais.

${ }^{4}$ Organização Mundial de Saúde: Agência especializada em saúde, subordinada à Organização das Nações Unidas e tem por objetivo desenvolver ao máximo possível o nível de saúde de todos os povos.
} 
conhecimentos prévios que os estudantes desta escola possuem sobre o que são os agrotóxicos, quais os malefícios e benefícios do seu uso, qual a relação existente entre os agrotóxicos e o meio ambiente, e qual a relação que existe entre os agrotóxicos e o estudo da Química.

A descrição dos conhecimentos e sentimentos dos estudantes em relação ao tema agrotóxicos é de suma importância, pois pode representar uma ferramenta estratégica para monitorar e fomentar mudanças de atitudes, de posicionamentos e de opiniões, considerando o pressuposto de que a sensibilização por meio do conhecimento dos agrotóxicos com enfoque nas inter-relações CTSA, apresenta contribuições significativas na perspectiva de uma formação voltada para a cidadania global em uma forte conexão com o princípio da educação ambiental.

\section{FUNDAMENTAÇÃO TEÓRICA}

O Ensino de Ciências Naturais é um grande desafio para a Educação no Brasil. Mesmo com o acesso facilitado a uma grande quantidade de informações e materiais disponibilizados tanto em livros quanto nos meios digitais, professores e estudantes ainda possuem uma grande dificuldade em compreender como o conhecimento científico pode se relacionar com seu cotidiano. Dessa forma, os docentes devem buscar estar sempre atualizados e utilizarem ferramentas e metodologias que facilitem o processo de ensino de Ciências.

No ano de 2017, o Ministério da Educação (MEC) propôs uma nova estrutura para se trabalhar o currículo escolar na Educação Básica. A Base Nacional Comum Curricular (BNCC) traz orientações e define habilidades e competências, que não são novas, para se trabalhar um currículo comum na Educação Básica. Sobre isso, a BNCC esclarece que:

Ao definir essas competências, a BNCC reconhece que a educação deve afirmar valores e estimular ações que contribuam para a transformação da sociedade, tornando-a mais humana, socialmente justa e, também, voltada para a preservação da natureza, mostrando-se também alinhada à Agenda 2030 da Organização das Nações Unidas (ONU) (BRASIL, 2017, p. 8).

De acordo com essas diretrizes, deve-se orientar os estudantes sobre questões de desenvolvimento sustentável, de maneira que eles possam utilizar os conhecimentos aprendidos em sala de aula para melhorar e tornar mais justa a comunidade em que vivem, valorizando a natureza e as relações existentes entre essa e nós.

Diante de tantas mudanças, tanto no meio econômico, social, ambiental e educacional, o ideal é que os educadores se mantenham atualizados e busquem alternativas eficazes para o enfrentamento dos entraves à educação de qualidade. Segundo Leite (2015): 
Em relação à realidade (e ao contexto), é importante que o professor esteja preparado, pois a realidade da escola que estamos pode mudar e se essas mudanças ocorrem, o professor deve estar preparado. Nosso papel de docente contemporâneo implica estarmos capacitados para ensinar em ambientes com os mais diversos recursos didáticos (LEITE, 2015, p. 25).

Mais do que isso, os professores devem estar preparados para mudar a realidade da escola e de seus estudantes. O processo de mudança deve começar por cada um dos profissionais da educação. Nesse sentido, a busca por novas informações, novos materiais e novas metodologias deve ser constante na profissão docente, mas não é suficiente que se tenha o conhecimento científico e acesso a novos materiais. O trabalho desse conhecimento deve ser colocado em prática, utilizando-se estratégias de ensino que estimulem os estudantes a desenvolverem habilidades e competências para que consigam articular os conhecimentos científicos dentro e fora da sala de aula. Nesse sentido, a BNCC corrobora que uma das competências gerais da Educação Básica é:

Exercitar a curiosidade intelectual e recorrer à abordagem própria das ciências, incluindo a investigação, a reflexão, a análise crítica, a imaginação e a criatividade, para investigar causas, elaborar e testar hipóteses, formular e resolver problemas e criar soluções (inclusive tecnológicas) com base nos conhecimentos das diferentes áreas (BRASIL, 2017, p. 9).

Nessa perspectiva, e diante do atual cenário mundial em que se está inserido, de enorme preocupação com problemas ambientais e os consequentes problemas de saúde, é importante que pesquisadores e professores reconheçam o contexto histórico e cultural em que estão inseridos, sendo importante que sejam propostas estratégias para contextualizar os conteúdos curriculares, articulá-los e torná-los significativos para os estudantes, levando em consideração a realidade local e cultural de cada um, a ética, o meio ambiente, o processo produtivo, tecnológico e social.

Constata-se que o tema agrotóxico é um assunto ainda pouco abordado no estudo tanto da Química quanto de outras disciplinas na área das Ciências Naturais. Através de pesquisa realizada em 2019 se verificou, por exemplo, que até o momento existem apenas dois artigos publicados na revista Química Nova na Escola que trabalharam essa temática para contextualizar o ensino de Química. Além disso, analisando as seis coleções de livros didáticos de Química do Ensino Médio, aprovados na avaliação do Plano Nacional do Livro Didático (PNLD) 2018-2020, constatou-se que o assunto é abordado apenas como citações ou simples exemplos, como a história do DDT, sua utilização como arma química e como agrotóxico. Algumas coleções também relacionam os agrotóxicos com o meio ambiente e com a poluição 
das águas, mas nem todas as coleções se referem a esses assuntos. Apenas uma coleção apresenta os agrotóxicos com uma abordagem mais evidente, informativa e crítica.

Para Fernandes e Stuani (2015), os agrotóxicos são um problema de âmbito muito abrangente, pois afetam tanto os sujeitos do campo, que trabalham diretamente na lavoura ou apenas consomem os produtos, quanto os sujeitos da zona urbana, que apenas consomem os alimentos produzidos nessas lavouras. Em virtude disso se pode considerar que a maioria da população de todo país, direta ou indiretamente, sofre exposição aos agrotóxicos, levando em consideração o uso intensivo desses compostos químicos nas lavouras brasileiras.

A preocupação de se trabalhar com essa temática com os estudantes do Ensino Médio surge do contexto social dos mesmos e da relevância do assunto para a sociedade em que estão inseridos. A Base Nacional Comum Curricular (BNCC) do Ensino Médio visa como uma das competências gerais da Educação Básica:

Valorizar a diversidade de saberes e vivências culturais e apropriar-se de conhecimentos e experiências que lhe possibilitem entender as relações próprias do mundo do trabalho e fazer escolhas alinhadas ao exercício da cidadania e ao seu projeto de vida, com liberdade, autonomia, consciência crítica e responsabilidade (BRASIL, 2017, p. 9).

Nesse sentindo, é importante o trabalho com assuntos que envolvam o contexto social dos estudantes, despertando interesse, motivação e ressignificando a aprendizagem de maneira que eles possam se relacionar melhor com o mundo. A formação do estudante deve ser integral, crítica, participativa, de maneira que ele possa interagir e melhorar sua vivência na comunidade. Assim, a metodologia com enfoque em Ciência, Tecnologia, Sociedade e Ambiente (CTSA) se torna uma forte ferramenta na formação de cidadãos críticos e participativos. De acordo com Santos e Schnetzler:

O ensino de Química para a cidadã e o cidadão deve estar centrado na inter-relação de dois componentes básicos: a informação química e o contexto social, pois para o cidadão participar da sociedade precisa não só compreender a Química, mas entender a sociedade em que está inserido (SANTOS; SCHNETZLER, 2015, p. 13).

O estudo da percepção ambiental e, nesse contexto, da percepção sobre os agrotóxicos, é pertinente para que se possam compreender as inter-relações entre o homem e a natureza, e entre o homem e o meio social em que vive. É importante também aprender a articular conteúdos relativos aos aspectos científicos, tecnológicos, sociais, econômicos e políticos, a fim de sensibilizar os indivíduos a perceberem o meio ambiente em que vivem, podendo dessa forma ajudar no desenvolvimento de metodologias para despertar nas pessoas a tomada de consciência frente aos problemas ambientais. Essa articulação faz com que os aprendizes, atores 
sociais, se apropriem de ferramentas culturais para atuar de forma participativa no mundo em que estão inseridos (SANTOS; AULER, 2011).

Ser um cidadão alfabetizado cientificamente, no sentido cívico, é buscar informações, analisar, compreender, reavaliar, criticar, expressar opiniões e argumentar sobre questões de ciência e tecnologia relacionadas, especialmente, com a vida cotidiana, o futuro próximo e imediato. Formar um cidadão crítico é permitir a melhora da sua qualidade de vida. "A partir do momento que o professor traz para a sala de aula situações com as quais o aluno se identifica, consegue uma das condições fundamentais para o aprendizado: a contextualização e consequentemente, a interação e aprendizado" (CORRÊA et al, 2019, p. 23).

Considerando a percepção que a população tem a respeito do Brasil ser um país em desenvolvimento, a abordagem dos agrotóxicos com enfoque em questões sociais também traz para discussão questões econômicas, políticas, culturais e éticas, que estão inter-relacionadas. Atualmente, a designação dos agrotóxicos por defensivos agrícolas sugere que esses supostamente protegem os cultivos e garantem o aumento da produtividade, mas, por outro lado, ocultam os efeitos deletérios desses produtos sobre a saúde humana e o meio ambiente. Para Fernandes e Stuani (2015, p. 749), no que se refere ao ensino de Ciências Naturais, os agrotóxicos são vistos como "um tema controverso, em razão das distintas visões sustentadas em relação às suas vantagens e desvantagens. Sendo, portanto, um produto do avanço científico e tecnológico, engloba na discussão relações entre Ciência, Tecnologia e Sociedade".

A abordagem temática sobre os agrotóxicos no viés da CTSA vem ao encontro das propostas de Freire (1970), que defende uma educação problematizadora, de descoberta da realidade, propiciando uma leitura crítica do mundo. Essa proposta teve sua origem na reflexão dialógica, com uma perspectiva de prática da liberdade, com seus temas geradores, promovendo conexões dos saberes do estudante e conteúdos programáticos normalmente trabalhados na Educação Básica. A partir de algumas estratégias de ensino é possível desenvolver uma abordagem temática de modo a implementar ações educativas, que permitam conhecer, interpretar e buscar soluções para os problemas que atingem a comunidade (MORAES et al, 2011). Por conseguinte, o trabalho com temáticas aparece como alternativa, uma vez que permite o desenvolvimento de um conjunto de conhecimentos de forma articulada, em torno de um eixo central, com objetos de estudo, conceitos, linguagens, habilidades e procedimentos próprios.

Cachapuz (2005) defende que o ensino de Ciências esteja articulado com as discussões e tomada de decisão sobre os impactos da Ciência e Tecnologia na sociedade. Assim, a 
abordagem CTSA se configura como uma importante estratégia no ensino de Ciências, ao promover uma educação voltada para a cidadania na medida em que promove o desenvolvimento de habilidades para esse fim, e ao estimular o questionamento e a crítica à concepção tradicional de Ciência como verdade absoluta, tentando explicitar o caráter provisório e inacabado das teorias científicas. Dessa forma, Formenton e Araújo (2015) expressam que:

As abordagens e as metodologias de ensino empregadas, envolvendo relações CTS ligadas às temáticas do meio ambiente, possibilitaram superar um ensino propedêutico, alavancando discussões e promovendo avanços em direção à almejada educação científica, valorizando aspectos de Educação Ambiental (FORMENTON; ARAÚJO, 2015, p. 39).

A Revolução Verde é apontada como o conjunto de iniciativas tecnológicas que transformou as práticas agrícolas e aumentou drasticamente a produção de alimentos no mundo. Um dos elementos em que a Revolução Verde se baseou foi a utilização intensiva de agrotóxicos, o que provocou mudanças no processo de produção que conduziram a problemas de ordem social em função, principalmente, da falta de qualificação para o manejo das novas tecnologias.

O uso excessivo de agrotóxicos leva à degradação do meio ambiente, contaminação de rios, trazendo consequências, em longo prazo, tanto para a natureza como para a saúde humana. Portanto, a utilização correta desses produtos é de fundamental importância para que sejam preservados os recursos naturais, que são essenciais para a propagação da vida humana e para as demais formas existentes de vida (SABADINI, 2014).

No que tange ao manuseio dos agrotóxicos nas lavouras, existem maneiras dos agricultores se protegerem quando estão manuseando os agrotóxicos, com a utilização dos Equipamentos de Proteção Individual (EPI), evitando assim intoxicações e possibilidade de desenvolverem doenças graves. Também se deve fazer o descarte correto das embalagens, realizando a tríplice lavagem e encaminhando-as para o destino correto. Esses fatores aliados ao correto uso dos agrotóxicos, observando os itens que se encontram em leis, que abordam este tema, podem amenizar os efeitos danosos ocasionados pelo uso desses produtos químicos. E, por outro lado, também se pode lançar mão de toda tecnologia existente para a produção de alimentos sem que seja necessário a utilização de agrotóxicos, os chamados alimentos orgânicos.

Outro aspecto importante é que, de modo geral, vários autores apresentam a temática agrotóxicos voltada apenas para o contexto agrícola, mas poucos falam do uso doméstico 
desses. Os produtos chamados domissanitários, que são saneantes de uso domiciliar, possuem alguns princípios ativos iguais aos dos agrotóxicos, só que em uma concentração bem menor. Então, além desses produtos químicos serem utilizados nas lavouras também podem estar presentes em inseticidas e produtos de desinfecção utilizados nas casas.

Diante desse cenário, o conhecimento dessas questões pelos estudantes e, consequentemente, a sensibilização deles é extremamente relevante para que possam ser tomadas medidas e ações, que venham promover uma mudança de percepção e de atitude perante a utilização dos agrotóxicos. É necessária uma discussão com novas ideias e tecnologias, que venham corroborar para uma mudança no paradigma errôneo vigente, visando apenas alternativas de produção, sem levar em consideração a preocupação ambiental (SABADINI, 2014).

\section{Processos metodológicos}

A opção metodológica que orientou esta pesquisa foi a de abordagem predominantemente qualitativa, uma vez que a natureza dos dados e sua análise se constituiu em uma abordagem mais textual e descritiva. De acordo com Ludke e André (1986), essa linha metodológica preza o ambiente natural como sua fonte de dados, e o pesquisador como seu principal instrumento, valorizando a descrição dos dados coletados. As metodologias qualitativas privilegiam, de modo geral, a análise de microprocessos, através de estudo das ações individuais e grupais. Silva e Menezes (2005) resumem bem as características da pesquisa qualitativa explicitadas acima como sendo uma pesquisa que:

Considera que há uma relação dinâmica entre o mundo real e o sujeito, isto é, um
vínculo indissociável entre o mundo objetivo e a subjetividade do sujeito que não pode
ser traduzido em números. A interpretação dos fenômenos e a atribuição de
significados são básicas no processo de pesquisa qualitativa. Não requer o uso de
métodos e técnicas estatísticas. O ambiente natural é a fonte direta para coleta de
dados e o pesquisador é o instrumento-chave. É descritiva. Os pesquisadores tendem
a analisar seus dados indutivamente. O processo e seu significado são os focos
principais de abordagem (SILVA; MENEZES, 2005, p. 20).

Considerando os pressupostos de um estudo qualitativo, o percurso metodológico adotado neste trabalho consistiu em uma divisão em quatro etapas simultâneas e interdependentes: a exploratória, a elaboração e a aplicação dos instrumentos de produção de dados, a análise e as conclusões.

A fase exploratória ocorreu, basicamente, com a análise da presença do tema agrotóxicos nos livros didáticos de Química aprovados pelo Programa Nacional do Livro e Materiais Didáticos (PNLD) 2018-2020, visando observar como esse tema é trabalhado, com 
qual conteúdo esse é articulado e em qual série. Os livros didáticos (LD), oferecidos pelo PNLD, são a ferramenta mais utilizada pelos professores e estudantes para organizar, consultar e estudar os conteúdos da disciplina. Mesmo com os avanços tecnológicos, metodologias diferenciadas e novos materiais, muitas escolas não possuem acesso a essas e, dessa maneira, o LD continua, para muitos, sendo o principal instrumento de ensino e aprendizagem.

A elaboração do instrumento de pesquisa (produção de dados) ocorreu com a organização de um questionário autoaplicável online. O questionário foi elaborado com o auxílio da plataforma Google formulários, e seu posterior envio ao grupo de WhatsApp de cada turma. Para tanto o questionário foi estruturado com trinta e três questões (das quais nove eram discursivas), objetivando obter informações sobre: caracterização dos estudantes e das famílias, conhecimento prévio sobre os agrotóxicos, sua utilização, problemática ambiental, relação com a alimentação e a saúde, presença nas casas e técnicas de produção de alimentos sem a utilização de agrotóxicos.

A aplicação do questionário, terceira etapa do percurso metodológico, foi realizada com 46 estudantes do terceiro ano do Ensino Médio da Escola Estadual Ulisses Guimarães (os quais aceitaram participar da pesquisa), situada no município de Campo Verde - Mato Grosso (MT), tendo sido a coleta de dados realizada no mês de novembro e dezembro de 2019, visando colher informações pertinentes à pesquisa. A escola foi escolhida por estar em um município cuja fonte de economia é a agricultura, e a mesma trabalha com o Ensino Médio e atende os estudantes vindos tanto da zona rural como da zona urbana do município. Esse fator se torna importante no sentido de que os estudantes da zona rural possuem um contato ainda maior em relação aos agrotóxicos, do que os estudantes da zona urbana. A escola possui cerca de 810 estudantes, distribuídos em dez turmas de $1^{\circ}$ ano, 7 turmas de $2^{\circ}$ ano e 6 turmas de $3^{\circ}$ ano, de acordo com dados da secretaria da escola no ano de 2019.

Na última etapa se utilizou a Análise Textual Discursiva (ATD) como método de análise dos dados coletados. Conforme Moraes e Galiazzi (2016), a ATD possibilita a emergência de novas compreensões sobre o assunto de investigação. A partir do momento em que os textos analisados são fragmentados em unidades de significados (unitarização) e, depois, reconstruídos por meio de uma interpretação profunda e minuciosa (categorização) surgem compreensões mais elaboradas, caracterizando metatextos de significados, nos quais foram unidas as palavras que trazem o mesmo significado em um grupo reduzido, descrevendo e interpretando os significados que o pesquisador constrói ou elabora a partir do referido corpus (MORAES; GALIAZZI, 2016). 


\section{Resultados e Discussões}

A seguir são apresentados os resultados do questionário aplicado e a análise dos dados inferidos a partir desses.

\subsection{CaracterizaÇão dos SUJEITOS}

Os estudantes participantes da pesquisa apresentam idade entre 16 e 20 anos, e são concluintes do Ensino Médio. Destes, 10\% residem na área rural do município e se deslocam todos os dias para a escola através do transporte escolar fornecido pelo município. Foi possível verificar que $43 \%$ dos estudantes possuem pelo menos um dos pais trabalhando em profissões ligadas diretamente ao ramo agrícola, conforme demonstrado nas Figuras 1 e 2, como: agricultores, engenheiros agrônomos, caminhoneiros, operadores de máquinas agrícolas, entre outros.

Figura 1 - Profissão do pai

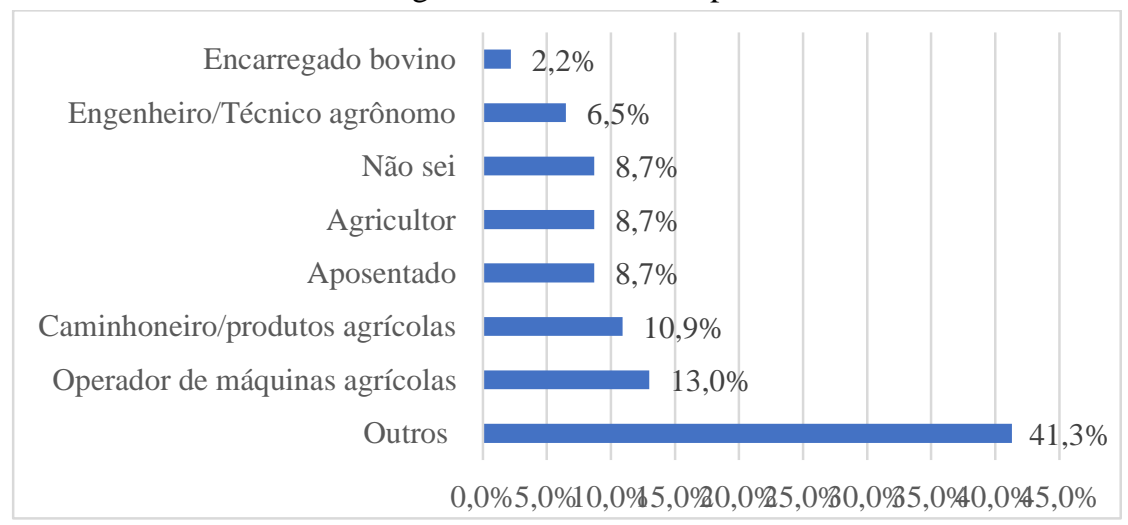

Fonte: Elaboração dos autores (2019).

Figura 2 - Profissão da mãe

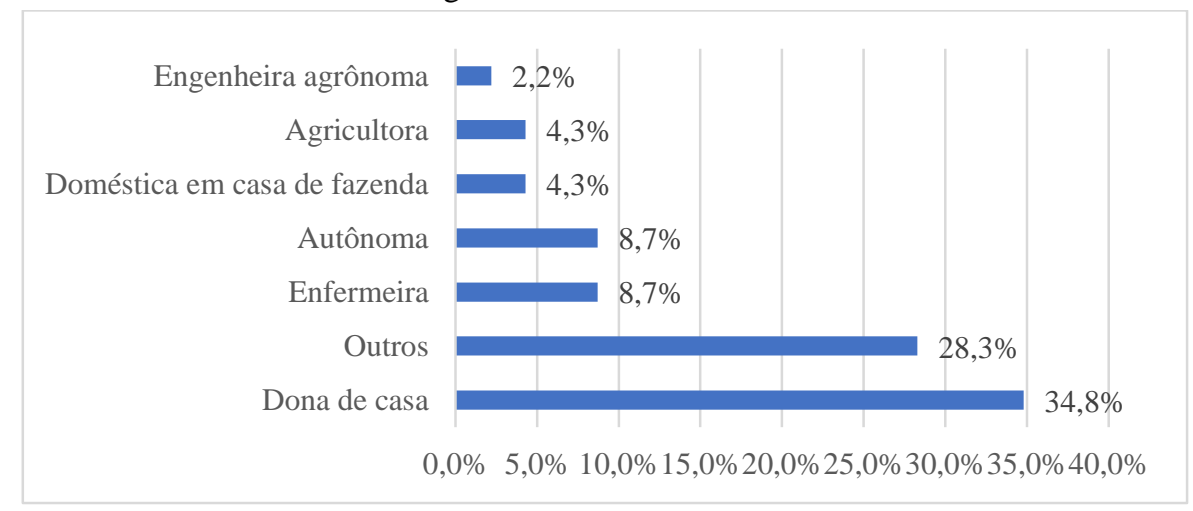

Fonte: Elaboração dos autores (2019).

Esses dados confirmam a influência que o setor agrícola tem no município de Campo Verde - MT, e a relação dos estudantes nesse contexto demonstra a importância e a pertinência de se debater a temática dos agrotóxicos, visto ser um assunto presente no cotidiano deles. 
Diante dos dados acima, recorda-se que Zappe (2011) afirma que na medida em que o estudante já traz da sua vida diária um determinado conhecimento, outros saberes podem ser reconstruídos a partir desse conhecimento, ampliando-o, complexificando-o, possibilitando ao sujeito compreender mais coisas para saber explicar melhor os fenômenos com os quais entra em contato.

\subsection{Diagnóstico QuANTO À PERCEPÇÃo PRÉvia dos ESTUdANTES SOBRE OS AGROTÓXICOS}

Quando questionados sobre o que são os agrotóxicos houve diversas respostas que foram categorizadas, conforme a Tabela 1.

Tabela 1 - O que são agrotóxicos na visão dos estudantes do $3^{\circ}$ ano do Ensino Médio da E. E. Ulisses Guimarães

\begin{tabular}{l|c}
\hline \multicolumn{1}{c|}{ O que são agrotóxicos? } & Quantidade de respostas \\
\hline $\begin{array}{l}\text { São produtos utilizados para defender as plantações de pragas ou } \\
\text { insetos }\end{array}$ & 14 \\
\hline Veneno ou produtos químicos tóxicos & 11 \\
\hline São substâncias/produtos químicos usadas na agricultura & 09 \\
\hline São defensivos agrícolas & 05 \\
\hline São substâncias utilizadas para combater doenças nas plantações & 05 \\
\hline $\begin{array}{l}\text { São produtos utilizados para o desenvolvimento mais rápido das } \\
\text { plantas, colaborando com a agricultura }\end{array}$ & 03 \\
\hline $\begin{array}{l}\text { São produtos químicos, físicos ou biológicos, com o objetivo de alterar } \\
\text { a composição química tanto da flora quanto da fauna a fim de } \\
\text { preservá-las. }\end{array}$ & 02 \\
\hline São substâncias utilizadas para matar fungos e bactérias na lavoura. & 01 \\
\hline São fertilizantes & 01 \\
\hline
\end{tabular}

Fonte: Elaboração dos autores (2019).

A categorização foi realizada mediante análise das respostas discursivas dos estudantes, portanto, uma única resposta pode ter relação com mais de uma categoria. Percebe-se que os estudantes possuem entendimentos relacionados à composição e utilização dos agrotóxicos, o que pode ser consequência da presença desses produtos na realidade deles.

Tais percepções podem estar relacionados com o posicionamento do próprio estudante quanto à dialética função exercida pelos agrotóxicos. A maioria dos estudantes (14) percebe os agrotóxicos como produtos que defendem as plantações de pragas e insetos. Verificando a quantidade de pais, que possuem ocupações ligadas à área agrícola, se pode considerar que os estudantes estão admitindo que os insetos são pragas e que necessitam dos agrotóxicos para seu controle, o que vem ao encontro do discurso que impera na região agrícola de Campo VerdeMT. 
Resultados semelhantes foram obtidos por Goes e Campos (2019), em pesquisa realizada com estudantes de uma escola do campo no assentamento rural Eli Vive, distrito de Lerroville, Londrina-PR, em que os estudantes também descreveram os agrotóxicos como veneno utilizado na produção de alimentos e no combate de pragas e doenças.

Em relação à presença dos agrotóxicos nos alimentos foi proposta a seguinte pergunta: No seu entendimento todos os alimentos oriundos da agricultura possuem algum tipo de agrotóxicos? Explique o porquê. A Tabela 2 mostra as categorias de respostas dos estudantes.

Tabela 2 - Presença dos agrotóxicos nos alimentos oriundos da agricultura, segundo os estudantes

\begin{tabular}{l|c}
\multicolumn{1}{c|}{ Presença dos agrotóxicos nos alimentos } & Quantidade de respostas \\
\hline $\begin{array}{l}\text { Estão presentes, pois durante todo processo de sua produção, desde o } \\
\text { plantio até a colheita, foi utilizado algum tipo de agrotóxico para } \\
\text { controle de pragas e doenças. }\end{array}$ & 25 \\
\hline $\begin{array}{l}\text { Nem sempre os agrotóxicos estão presentes. Existem alimentos } \\
\text { produzidos de forma natural que não possuem agrotóxicos, como os } \\
\text { orgânicos e na agricultura familiar. }\end{array}$ & 16 \\
\hline $\begin{array}{l}\text { Estão presentes, porque se tiver plantações grandes de qualquer coisa e } \\
\text { passar um agrotóxico o vento vai levar isso para as plantações } \\
\text { pequenas também. }\end{array}$ & 02 \\
\hline $\begin{array}{l}\text { Estão presentes, porque não há outra maneira de defendermos as } \\
\text { lavouras contra os insetos e ervas daninhas. }\end{array}$ & 02 \\
\hline $\begin{array}{l}\text { Estão presentes, mesmo que digam que não possuem, sempre existe um } \\
\text { pouco de agrotóxicos. }\end{array}$ & 01 \\
\hline
\end{tabular}

Fonte: Elaboração dos autores (2019).

Com os dados da Tabela 2, constata-se que os estudantes que acreditam que há a possibilidade da produção de alimentos sem a presença de agrotóxicos são, na maioria, os que moram na zona rural, conforme dados de sua caracterização no questionário, e fazem parte do programa de agricultura familiar, em que os pais têm uma relação mais próxima com o setor agrícola. E para maioria dos estudantes não há como produzir alimentos sem agrotóxicos.

Em outra questão foi perguntado aos estudantes se eles entendem que existem maneiras de produzir alimentos sem a utilização de agrotóxicos e de que forma isso pode ocorrer. Alguns entraram em contradição em relação às respostas mencionadas na Tabela 2 , pois de acordo com a Figura 3, para 17,4\% dos estudantes não há como produzir alimentos sem agrotóxicos, para 19,6\% dos estudantes há como produzir alimentos sem agrotóxicos, 18,9\% dos estudantes não sabem, e para 52,2\% dos estudantes existe a possibilidade de produzir alimentos sem agrotóxicos, de maneira natural e orgânica, mas apenas em pequenas plantações. 
Figura 3 - Existência de maneiras de produzir alimentos sem a utilização de agrotóxicos

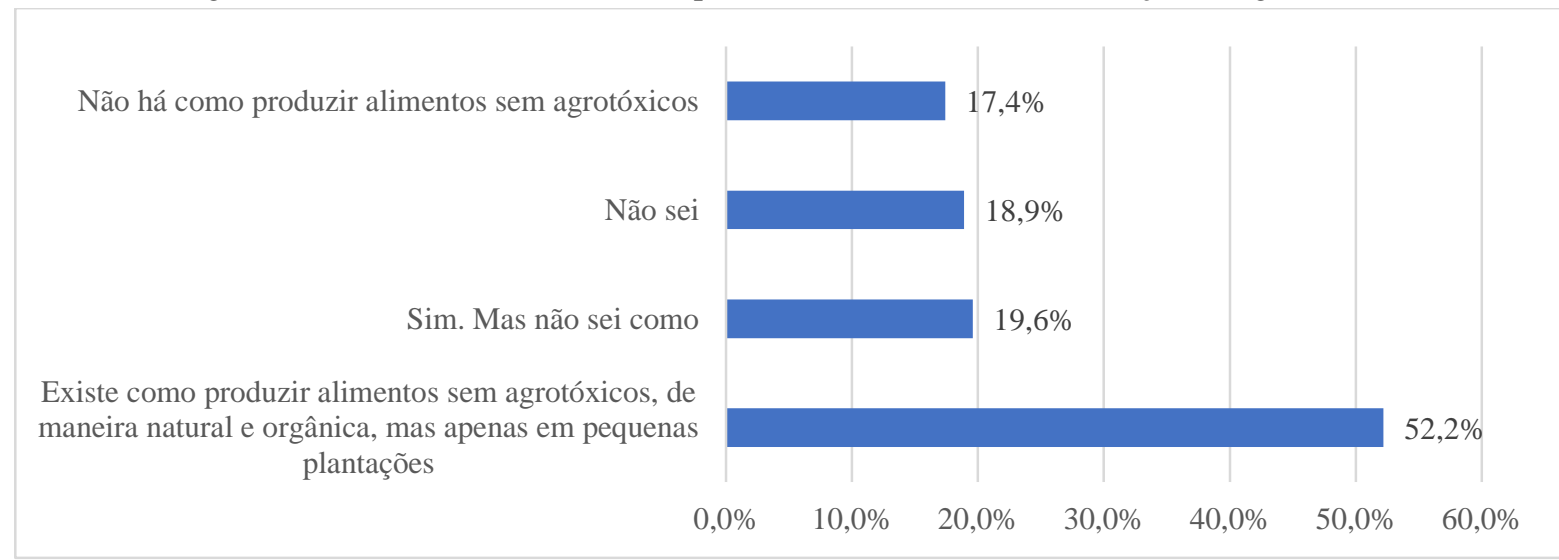

Fonte: Elaboração dos autores (2019).

Esses dados revelam que ainda há dúvidas e contradições em relação à utilização ou não dos agrotóxicos nas plantações, bem como às formas alternativas de combater as ervas daninhas e as pragas que atacam as mesmas. Os estudantes enxergam a produção de alimentos sem agrotóxicos, na maioria das vezes, apenas em pequena escala, na agricultura familiar, em hortas ou estufas. Verifica-se aqui uma contradição quanto ao que os estudantes percebem sobre a presença de agrotóxicos nos alimentos (28 estudantes acreditam que os agrotóxicos estão presentes em todos os alimentos) e a existência de maneiras de produção sem a utilização de agrotóxicos (33 estudantes acreditam que há como produzir alimentos sem agrotóxicos).

Percebe-se, dessa forma, a necessidade de conhecimentos específicos relacionados à produção orgânica de alimentos, bem como formas alternativas de controle de pragas e doenças nas plantações, as tecnologias disponíveis e as relações sociais e econômicas existentes nesse contexto, relacionando esses saberes com conhecimentos científicos. Assim, Santos e Schnetzler (2015) corroboram ao expressar que:

\footnotetext{
A transmissão desses conhecimentos deve ser encharcada na realidade, e isto não significa o reducionismo que virou um modismo Química do cotidiano (às vezes, apenas utilitarismo), mas ensinar Química dentro de uma concepção que destaque o papel social da mesma, mediante uma contextualização social, política, filosófica, histórica, econômica e (também) religiosa. [...] (SANTOS; SCHNETZLER, 2015, p. 12-13).
}

Em relação à presença de agrotóxicos nos alimentos que são consumidos, a maioria dos estudantes concorda que para retirar os agrotóxicos é necessário lavar os mesmos com uma solução de água e bicarbonato de sódio ou iodo, conforme a Figura 4. 
Figura 4 - Maneiras de retirar o agrotóxico dos alimentos

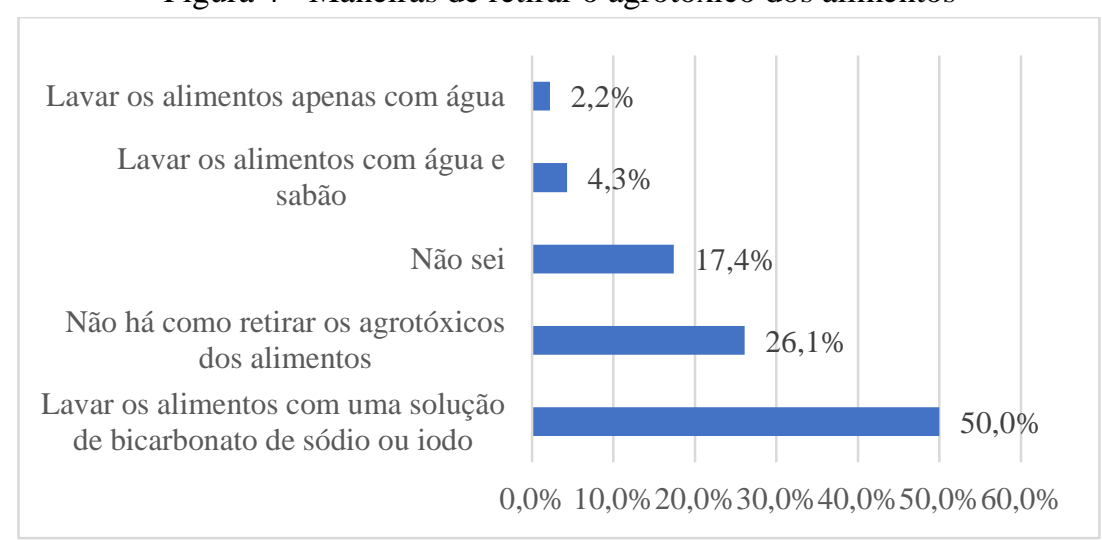

Fonte: Elaboração dos autores (2019).

Estudo realizado pelo departamento de Veterinária e Ciências Animais da Universidade de Massachussets, nos EUA, em 2017, mostra que lavar maçãs por 15 minutos em uma solução de bicarbonato de sódio a $1 \%$ diluído em água $(10 \mathrm{mg} / \mathrm{mL})$ foi suficiente para remover praticamente todo o resíduo de agrotóxicos da superfície das frutas (YANG et al, 2017). O estudo compara ainda o uso do bicarbonato com outras medidas de limpeza de frutas comumente utilizadas e conclui que seu uso foi mais eficiente que a lavagem com água ou com uma solução comercial à base de cloro. No entanto, deve-se tomar cuidado com estas informações, pois o estudo foi realizado analisando a presença de apenas dois agrotóxicos. É necessária toda uma atenção quanto ao tempo entre as aplicações dos agrotóxicos e a colheita e consumo dos alimentos, e também se deve levar em consideração que o bicarbonato não retira o agrotóxico que penetrou na casca da fruta.

Portanto, mesmo as respostas dos estudantes sendo satisfatórias, pode-se utilizar esses conhecimentos para contextualizar conteúdos químicos como solubilidade, volatilidade, funções orgânicas, concentração, entre outros.

O princípio ativo presente em alguns agrotóxicos também pode estar presente em vários produtos que são utilizados dentro das casas, tendo como diferença apenas a concentração desse princípio ativo. A legislação brasileira diferencia os produtos empregados na agricultura dos utilizados em ambientes confinados. O primeiro, segundo a Lei $\mathrm{n}^{\circ} 7.802$, de 11 de julho de 1989, é classificado como agrotóxico, e os produtos químicos usados em ambientes confinados são classificados, de acordo com a Lei n 6.360, de 23 de setembro de 1976, como saneantes domissanitários. A definição de domissanitários, conforme essa lei, é dada como: "Substância ou preparação destinada à higienização, desinfecção ou desinfestação domiciliar, em ambientes coletivos ou públicos" (BRASIL, 1976, p.1). 
Esses produtos, usados para o controle de vetores no ambiente domiciliar, são inseticidas principalmente do grupo químico dos piretroides e piretrinas, e estão entre as principais causas de intoxicação no ambiente doméstico, causando manifestações alérgicas especialmente em crianças. Os consumidores, na maioria das vezes, desconhecem as propriedades tóxicas dos componentes das formulações. A banalização do consumo dessas substâncias químicas no ambiente doméstico, bem como o uso contínuo e simultâneo de várias delas, evidencia um risco elevado para a saúde pública e para o meio ambiente.

Pensando nesse contexto foi perguntado aos estudantes se eles utilizam algum pesticida em suas casas e qual seria este pesticida. As respostas estão ilustradas na Figura 5.

Figura 5 - Utilização de pesticidas em casa

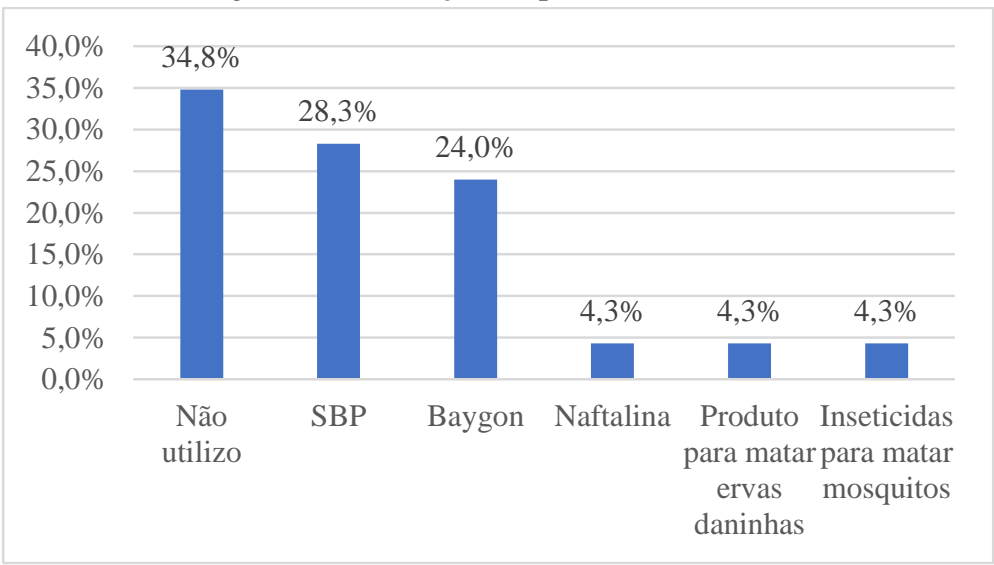

Fonte: Elaboração dos autores (2019).

Em seguida foi perguntado quais produtos eles utilizam em casa, entre uma tabela com onze produtos mais comuns de uso doméstico. As respostas são representadas na Figura 6.

Figura 6 - Produtos utilizados nas residências dos estudantes

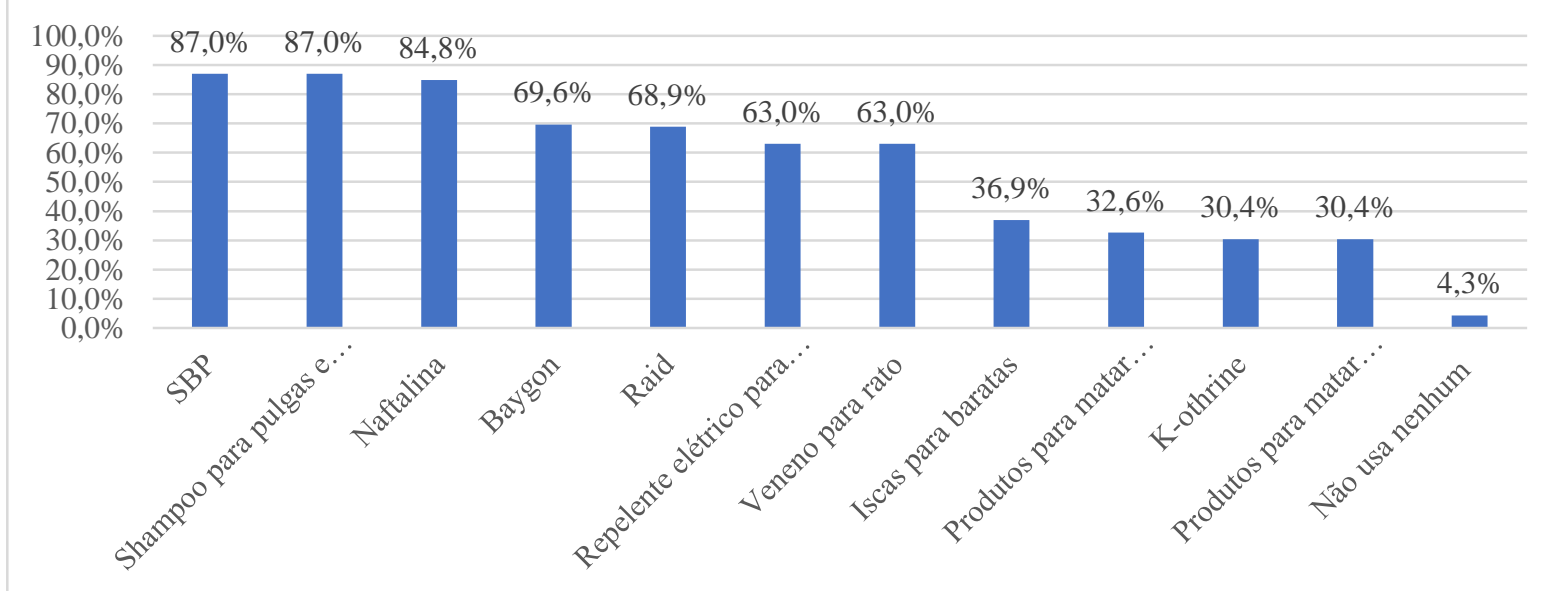

Fonte: Elaboração dos autores (2019). 
Fazendo a comparação entre as respostas, registradas nos gráficos 5 e 6 , se percebe que os estudantes não fazem a relação entre vários pesticidas com os produtos que são utilizados nas casas. São necessárias uma compreensão e uma articulação maior entre o que se estuda em sala de aula, com situações presentes na comunidade e dentro da própria casa.

A maioria dos estudantes pesquisados tem conhecimento sobre os malefícios e benefícios causados pelo uso dos agrotóxicos. Quando questionados sobre quais são os benefícios da utilização dos agrotóxicos, $50 \%$ responderam que era o controle de pragas nas lavouras, $28 \%$ que era o aumento da produtividade e $21,7 \%$ que era a produção de produtos de melhor qualidade (Figura 7).

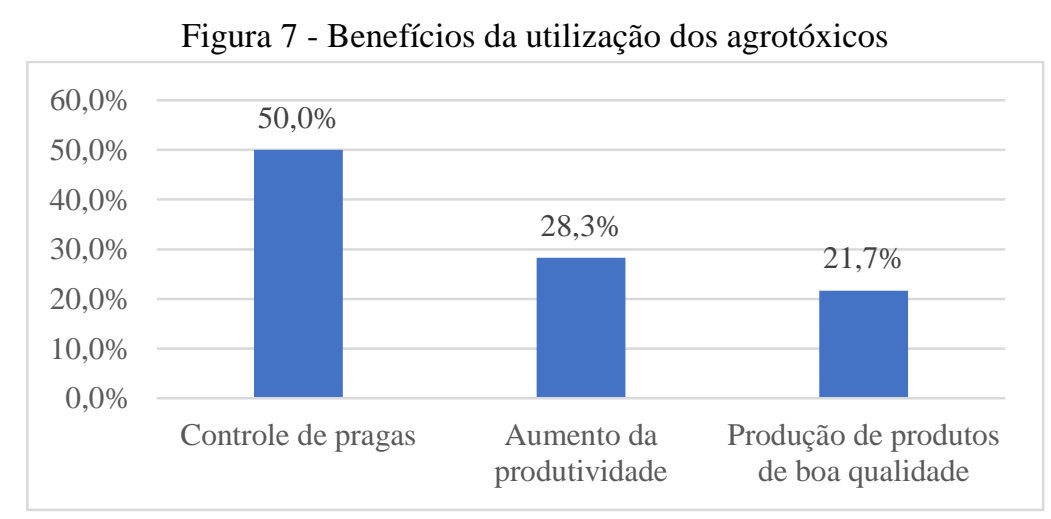

Fonte: Elaboração dos autores (2019).

Em relação aos malefícios causados pela utilização dos agrotóxicos, 76\% dos estudantes responderam que os mesmos são prejudiciais à saúde humana, 26,1\% que são prejudiciais ao meio ambiente, poluindo o solo, a água e o ar, e 4,3\% que são prejudiciais aos animais (Figura $8)$.

Figura 8 - Malefícios da utilização dos agrotóxicos

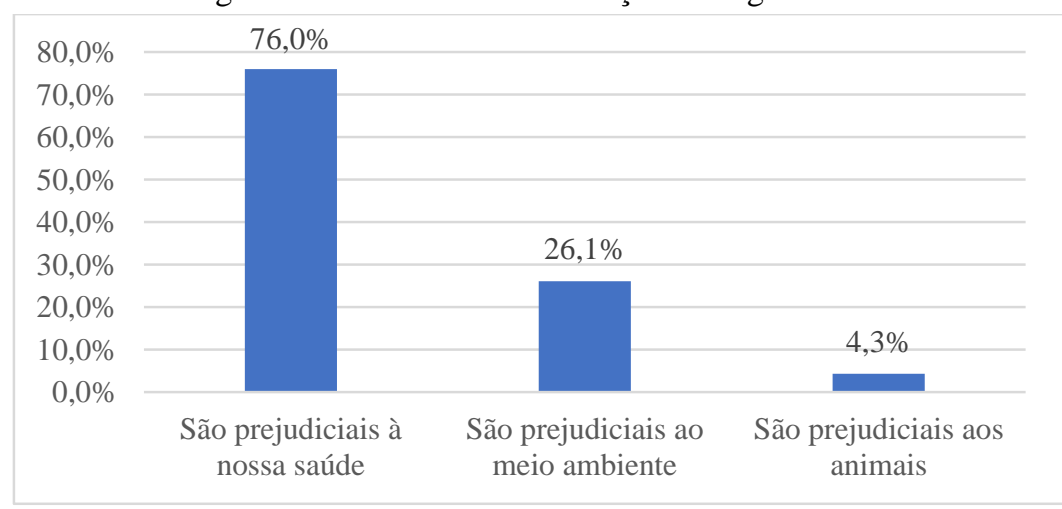

Fonte: Elaboração dos autores (2019).

A percepção dos estudantes em relação aos benefícios (Gráfico 7) e malefícios (Gráfico 8) da utilização dos agrotóxicos demonstra um senso comum importante, ou seja, os agrotóxicos são importantes para a produção agrícola e para a economia, e isso justifica seu uso mesmo 
sendo nocivo para a saúde das pessoas, dos animais e do meio ambiente. Verifica-se aqui o quanto controverso é a temática dos agrotóxicos e quão importante e necessária é a abordagem desse assunto no meio escolar. O uso exagerado e inadequado de agrotóxicos causa impactos à saúde humana dos aplicadores, dos produtores, dos moradores da comunidade e dos consumidores dos alimentos que estão contaminados por compostos químicos, tornando-se um grave problema de saúde pública em geral.

Em pesquisa realizada por Sabadini (2014) foram observados resultados diferentes na percepção dos estudantes sobre os malefícios dos agrotóxicos. Para os estudantes de Santa Terezinha-RS, o maior problema causado por agrotóxicos está na poluição ambiental e apenas 13,6\% dos estudantes consideram os maiores malefícios sendo os prejuízos à saúde humana. No entanto, se percebe que os dois grupos de estudantes pesquisados, os da pesquisa de Sabadini (2014) e da presente pesquisa, relacionaram os problemas ambientais e de saúde causados pelos agrotóxicos.

Sobre a relação entre os agrotóxicos e a Química, 82,6\% dos estudantes responderam que é possível relacionar o tema com conceitos estudados na disciplina de Química como, por exemplo, concentrações, funções orgânicas e reações químicas. Ainda sobre essa relação, $91 \%$ responderam que o agrotóxico é um tema interessante e importante para se trabalhar na disciplina de Química, e apenas 41,3\% responderam que já trabalharam com essa temática em sala de aula. Resultados com alguma semelhança também foram observados nas pesquisas de Zappe (2011), Sabadini (2014) e Buffolo (2014).

Coadunados com a perspectiva de se trabalhar temas na abordagem CTSA, que estão presentes no cotidiano dos estudantes com a perspectiva de dar sentido ao ensino e, consequentemente, à aprendizagem, Zappe (2011), Sabadini (2014), Buffolo (2014) e Goes e Campos (2019) encontraram, também, no tema agrotóxicos, uma forma de articular e contextualizar os conteúdos químicos, e a alfabetização científica com assuntos atuais e relevantes para os estudantes, contribuindo para a formação de cidadãos críticos, participativos e aptos a tomarem decisões fundamentadas.

\section{CONSIDERaÇões}

Ao realizar um exame detalhado da compreensão dos estudantes sobre a temática agrotóxicos se verifica a necessidade de aproximação e de articulação entre os temas científicos, o enfoque CTSA e sua realidade, auxiliando-os na compreensão sobre a relação entre Ciência 
e Tecnologia imersa em um contexto que conglomere múltiplos aspectos relacionados ao sentido de construção, de fragmentação e de recontrução das ações e organizações humanas.

Os estudantes de Campo Verde-MT percebem os agrotóxicos como tema atual e importante a ser trabalhado em sala de aula. Eles possuem percepções básicas sobre o tema e conseguem relacioná-lo com a produção de alimentos, saúde humana, meio ambiente e a Química, mas de maneira superficial e controversa, necessitando assim de um aprofundamento mais específico e crítico sobre a temática. Vericou-se, também, que há interesse por parte dos estudantes de obterem mais informações sobre os agrotóxicos e concordam que há a possibilidade de relacionar o assunto aos conceitos químicos.

Nesse sentido, o tema agrotóxicos é um assunto pertinente e viável que possibilita a contextualização de conhecimentos das Ciências Naturais, de maneira a compreender um problema social controverso que envolve aspectos locais e globais, uma vez que a sociedade, de modo geral, tem sentido as implicações do uso indiscriminado de defensivos agrícolas nas lavouras. Diante desse fato, levar esse tema para sala de aula permite trabalhar com projetos de forma a suscitar ampla interação entre a Química, a Biologia, outras áreas do conhecimento e a realidade do estudante, efetivando-se a tão almejada interdisciplinaridade, através da contextualização dos conteúdos e a participação ativa dos estudantes na comunidade a qual pertence a escola (MORAES et al, 2011).

Compreende-se que o tema agrotóxico pode ser discutido em diferentes níveis de ensino e por diferentes áreas do conhecimento. No ensino de Ciências podem ser abordados aspectos ligados aos conteúdos conceituais e de âmbitos ambiental, político, social, histórico, econômico e ético, como também vários outros igualmente importantes para formação tanto de estudantes como de professores mais conscientes, críticos e ativos na sociedade. Inclui-se professores aqui, pois para que o trabalho com a temática acima mencionada seja eficaz, é necessária também a preparação do professor neste aspecto.

Embora os estudantes tenham apresentado visões bem variadas em relação aos agrotóxicos, desde sua importância para as plantações até os problemas causados ao meio ambiente e à saúde humana, essas não são as percepções que permeiam a sociedade de modo geral. De acordo com Fernandes e Stuani (2015, p. 758): “a ideologia do projeto de modernidade capitalista é estendida e divulgada nos meios de comunicação, e também na formação escolar como se fosse o modelo que expressa apenas impactos positivos e universais a população". Nesse sentido, o assunto que envolve os agrotóxicos pode ser considerado um tema científico e social controverso, o que foi possível perceber nas respostas dos estudantes, e 
como tal, oculta e omite suas contradições, e nesse seguimento é preciso, no espaço escolar, abordar as diferentes visões, aspectos e conceitos, contextualizá-las e entender suas apropriações e finalidades a respeito do tema. Para Reis (2007), a discussão de questões controversas em sala de aula é "[...] extremamente útil quer na aprendizagem dos conteúdos, dos processos e da natureza da ciência e da tecnologia, quer no desenvolvimento cognitivo, social, político, moral e ético dos alunos" (REIS, 2007, p. 125).

É considerando essa função dialética e controversa exercida pela temática dos agrotóxicos, e tendo em vista o cenário agrícola presente no município de Campo Verde-MT, que surgiu a presente proposta de pesquisa envolvendo o tema, cuja pretensão final é desenvolver um livro paradidático, que auxilie o professor a realizar uma articulação entre teoria e prática, entre conhecimento científico e problemas socioambientais. Assim, a abordagem do tema agrotóxicos, no ensino de Ciências Naturais, pode colaborar para os processos formativos, que contribuam para o desenvolvimento, nos estudantes, da capacidade de argumentação, de análise, de posicionamento crítico, de poder de decisão e de prática social diante de temas que interferem em suas vidas, contribuindo assim para a formação de cidadãos críticos e participativos.

\section{REFERÊNCIAS}

BRASIL. Lei 6.360/1976. Dispõe sobre a Vigilância Sanitária a que ficam sujeitos os Medicamentos, as Drogas, os Insumos Farmacêuticos e Correlatos, Cosméticos, Saneantes e Outros Produtos, e dá outras Providências. Diário Oficial da União, Brasília, 23 set. 1976.

BRASIL. Lei 7.802/1989. Dispõe sobre a Pesquisa, a Experimentação, a Produção, a Embalagem e Rotulagem, o Transporte, o Armazenamento, a Comercialização, a Propaganda Comercial, a Utilização, a Exportação, o Destino Final dos Resíduos e Embalagens, o Registro, a Classificação, o Controle, a Inspeção e a Fiscalização, de Agrotóxicos, seus Componentes, e Afins, e dá outras providências. Diário Oficial da União, Brasília, 12 jul. 1989.

BRASIL. Ministério da Educação. Secretaria de Educação Básica. Base Nacional Comum Curricular. Brasília, 2017. Disponível em: http://basenacionalcomum.mec.gov.br/images/BNCC_EI_EF_110518_versaofinal_site.pdf. Acessado em: 01 de mar. 2020

BUFFOLO, Andreia Cristina Cunha. Agrotóxicos: Uma proposta socioambiental reflexiva para desenvolver conhecimentos químicos numa perspectiva CTS. 2014. $122 \mathrm{f}$.

Dissertação. (Mestrado em Educação para a Ciência e a Matemática) Universidade Estadual de Maringá, Maringá, 2014. Disponível em:

https://sucupira.capes.gov.br/sucupira/public/consultas/coleta/trabalhoConclusao/viewTrabalh oConclusao.jsf?popup=true\&id_trabalho=1474592. Acessado em: 10 de jan. 2020. 
CACHAPUZ, Antonio. A superação das visões deformadas da Ciência e da Tecnologia: um requisito essencial para a renovação da educação científica. In: CACHAPUZ, Antonio; GILPÉREZ, Daniel; CARVALHO, Anna Maria; VILCHES, Amparo; PRAIA, João. (Orgs.). A necessária renovação do ensino de Ciências. São Paulo - SP: Editora Cortez, 2005.

CORRÊA, Márcia Lima; MEGGIOLARO, Graciela Paz; REIS, Ana Queli Mafalda. Abordagem do conteúdo de frações a partir do programa Nacional do Livro Didático. Revista de Ensino de Ciências e Matemática, v. 10, n. 6, p. 21-38, 2019. Disponível em: http://revistapos.cruzeirodosul.edu.br/index.php/rencima/article/view/1993/1212. Acessado em: 15 de fev. 2020.

FERNANDES, Carolina dos Santos., STUANI, Geovana Mulinari. Agrotóxicos no Ensino de Ciências: uma pesquisa na educação do campo. Revista Educação \& Realidade. Porto Alegre, v. 40, n. 3, p. 745-762, jul./set. 2015. Disponível em: http://www.scielo.br/pdf/edreal/v40n3/2175-6236-edreal-45796.pdf. Acessado em: 15 de fev. 2020.

FREIRE, Paulo. Pedagogia do Oprimido. Rio de Janeiro: Paz e Terra, 1970.

FORMENTON, Ricardo; ARAÚJO, Mauro Sérgio Teixeira de. Educação Sócio-ambiental desenvolvida sob o enfoque CTS entre alunos do curso técnico de nível médio em automação industrial do IFSP. Revista de Ensino de Ciências e Matemática, v.6, n. 1, p. 33-42, 2015. Disponível em:

http://revistapos.cruzeirodosul.edu.br/index.php/rencima/article/view/1032/730. Acessado em: 15 de fev. 2020.

GOES, Denilson Manfrin; CAMPOS, Margarida de Cássia. Uso de agrotóxicos e produção agroecológica: percepção de estudantes secundaristas de uma escola do campo. Revista Nera, Presidente Prudente, v. 22, n. 46, p. 58-78, jan./abr. 2019. Disponível em:

http://revista.fct.unesp.br/index.php/nera/article/view/5774/4680. Acessado em: 15 de fev. 2020.

LEITE, Bruno Silva. Tecnologias no Ensino de Química: teoria e prática na formação docente. 1. ed. Curitiba, Appris, 2015.

LUDKE, Menga; ANDRÉ, Marli E. D. A. Pesquisa em Educação: Abordagens

Qualitativas. São Paulo: EPU, 1986.

MORAES, Roque; GALIAZZI, Maria do Carmo. Análise Textual Discursiva. 3. ed. Ijuí: Ed. Unijuí, 2016.

MORAES, Priscila Cardoso., TRAJANO, Silvia Cristina de Souza., MAFFRA, Stella Maria., MESSEDER, Jorge Cardoso. Abordando agrotóxico no ensino de Química: uma revisão.

Revista Ciências \& Ideias. Rio de Janeiro. v. 3, n. 1, set. 2010/abr. 2011. Disponível em: https://revistascientificas.ifrj.edu.br/revista/index.php/reci/article/view/74/121. Acessado em: 20 de fev. 2020.

REIS, Pedro Rocha dos. Os temas controversos na educação ambiental. Pesquisa em Educação Ambiental, v. 2, n. 1, p. 125-140, 2007. Disponível em: 
https://www.periodicos.rc.biblioteca.unesp.br/index.php/pesquisa/article/view/6134. Acessado em: 20 de fev. 2020.

SABADINI, Lecí. Percepção dos alunos do $9^{\circ}$ ano da escola Santa Terezinha sobre os agrotóxicos. 2014. Trabalho de Conclusão de Curso (Especialização em Educação Ambiental), Universidade Federal de Santa Maria, Santa Maria, 2014. 37 f. Disponível em: https://repositorio.ufsm.br/bitstream/handle/1/11553/Sabadini_Leci.pdf?sequence=1\&isAllow ed=y. Acessado em: 15 de jan. 2020.

SANTOS, Wildson Luiz Pereira; AULER, Décio. (Org.) CTS e educação científica: desafios, tendências e resultados de pesquisas. Brasília: Editora Universidade de Brasília, 2011.

SANTOS, Wildson Luiz Pereira dos Santos; SCHNETZLER, Roseli Pacheco. Educação em Química: Compromisso com a cidadania. 4. ed. rev. atual. Ijuí: Ed. Unijuí, 2015.

SILVA, Edna Lúcia de; MENEZES, Estera Muszkat. Metodologia da Pesquisa e Elaboração de Dissertação. 4. ed. rev. atual. - Florianópolis: UFSC, 2005. Disponível em: https://projetos.inf.ufsc.br/arquivos/Metodologia_de_pesquisa_e_elaboracao_de_teses_e_diss ertacoes_4ed.pdf. Acessado em: 15 de jan. 2020.

YANG, Tianxi. DOHERTY, Jeffery. ZHAO, Bin. KINCHLA, Amanda. CLARK, John. HE Lili. Effectiveness of Commercial and Homemade Washing Agents in Removing Pesticide Residues on and in Apples. Journal of Agricultural and Food Chemistry, 2017. Disponível em: https://pubs.acs.org/doi/full/10.1021/acs.jafc.7b03118. Acessado em: 17 de abr. 2020.

ZAPPE. Janessa Aline. Agrotóxicos no contexto Químico e Social. 2011. 135 f. Dissertação. (Mestrado em Educação em Ciências) Universidade Federal de Santa Maria, Porto Alegre, 2011. Disponível em:

https://repositorio.ufsm.br/bitstream/handle/1/6647/ZAPPE\%2c\%20JANESSA\%20ALINE.pd f? sequence=1\&isAllowed=y. Acessado em: 10 de jan. 2020.

Recebido em: 02 de março de 2020.

Aprovado em: 22 de abril de 2020. 